\title{
The injury burden - sport and exercise scientists can contribute more to public health
}

\author{
Stafford C Rorke (DPhil, FACSM) \\ Wellness, Health Promotion and Injury Prevention Program, School of Health Sciences, Oakland University, Rochester, Michigan, USA
}

Correspondence to: Stafford Rorke (rorke@oakland.edu)

\section{Introduction}

Presentations delivered at the 14th Biennial South African Sports Medicine Congress in Johannesburg (18 - 20 October 2011) indicate that the South African Sports Medicine Association (SASMA) not only met, but exceeded expectations related to the conference theme 'From basics to brilliance - world class in Africa'. In my opinion (a visiting American scholar) SASMA demonstrated commitment to high-quality sports injury prevention, treatment, rehabilitation and management. More specifically, a significant step was taken towards embracing Exercise is Medicine $®$ (EIM), with an appeal to all sports medicine and allied health practitioners to expand the scope of public health intervention strategies. ${ }^{1,2}$ Consequently, the purpose of this commentary is to:

- alert readers to the global burden of unintentional and intentional injury

- advocate a greater public health injury prevention role for sports medicine and related allied health practitioners.

\section{Worldwide injury burden}

According to the World Health Organization (WHO, 2010) Violence and Injury Prevention unit: 'Injuries kill about 5.8 million people each year. This accounts for $10 \%$ of the world's deaths, $32 \%$ more than fatalities from malaria, tuberculosis and HIVIAIDS combined. Tens of millions more suffer injuries that lead to hospitalization, emergency treatment or other care. Among the causes of injury are acts of violence against others or oneself, road traffic crashes, burns, drowning, falls and poisoning. Nearly one third of the 5.8 million deaths from injuries are the result of violence - suicide, homicide and war - and nearly one quarter are the result of road traffic crashes.' (See Fig. $1^{3}$ )

'Injuries are a growing problem. Globally, the three leading causes of death from injuries are all predicted to rise in rank compared to other causes of death. Road traffic crashes are predicted to become the fifth leading cause of death by 2030 , with suicide and homicide rising to become the 12th and 18th leading causes of death respectively. Injuries affect all age groups but have a particular impact on young people. For people between the ages of 5 and 44 years, injuries are one of the top three causes of death. ${ }^{3}$

Given that injuries are a leading cause of death among young people, when combined, unintentional and intentional injury are a leading cause of years of potential life lost under age 65, ahead of coronary heart disease and cancer. ${ }^{4}$ Deaths represent only the tip of the iceberg:

'Deaths that result from injuries represent only a small fraction of those injured. Millions of people suffer injuries that lead to hospitalization, emergency department or general practitioner treatment, or treatment that does not involve formal medical care. The consequences of injuries and violence are significant .... leading

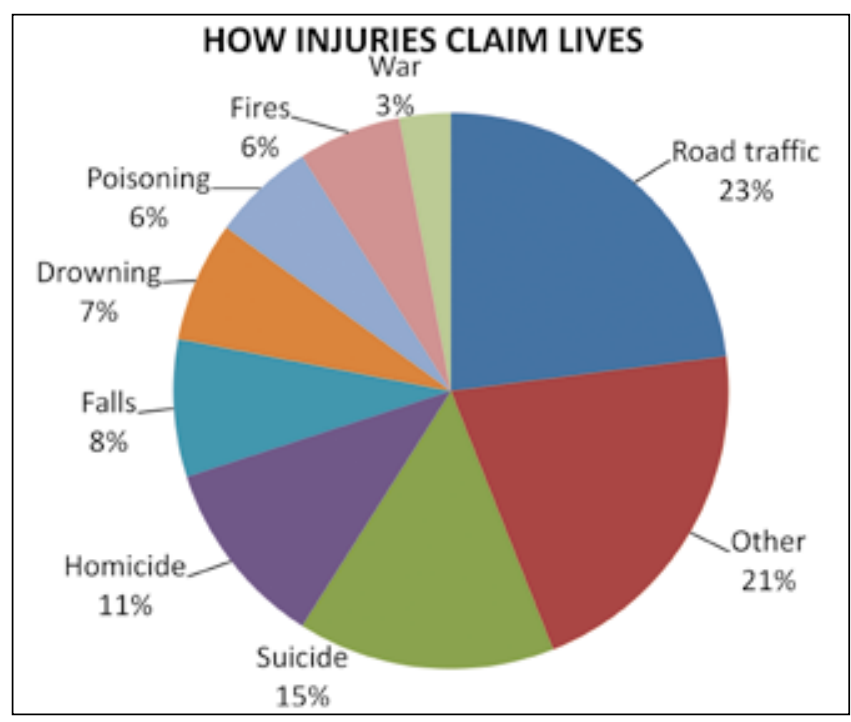

Fig. 1. How injuries claim lives. Reproduced with permission from the WHO (2010). ${ }^{3}$ (Other includes smothering, asphyxiation, choking, animal and venomous bites, hypothermia and hyperthermia, and natural disasters.)

to physical injuries, mental consequences (depression, anxiety), behavioural changes (smoking, alcohol and drug misuse, unsafe sexual practices, unwanted pregnancies); leading to death, disability, suicide, HIV and other STDs, cancer, cardio-vascular and other noncommunicable diseases. ${ }^{3}$

Almost twice as many men as women die as a result of injuries and violence each year. ${ }^{3}$ For men the three leading causes of death from injuries are road traffic injuries, suicide and homicide, while leading causes for women are road traffic injuries, suicide, and firerelated burns. ${ }^{3}$ For each type of injury (except injury resulting from fires), death rates are higher for men than for women. ${ }^{3}$ The economic burden of injury is staggering, as are injury disability statistics.

\section{Public health and injury}

Health professionals focus most primary health promotion efforts on prevention of degenerative diseases because these are the leading causes of death amenable to risk factor modification, and in the case of sports medicine focus on the prevention of sports injuries. However, is enough being done to prevent the overall burden of injuries?

\section{Paradigm shift: injuries are not 'accidents'}

Injuries occur in predictable patterns, a consequence of host (human), agent (energy or vector), and environment (physical and socio-cultural) interaction. Acute exposure to thermal, mechanical, electrical, or chemical energy, or lack of life-needed elements (heat or oxygen), causes injury. Unintentional injury, although unplanned, 
is typically preceded by an unsafe act or condition, yet people continue to speak of accidents. The word 'accident', although commonly used, is a vague, misleading term suggesting lack of understanding of the causes of injury, attributing injury to random chance, luck or fate. Consequently, many continue to think of injuries as haphazard, uncontrolled factors, rarely considering injury likely, or within personal control. Denial is often a factor. Little attention is paid to injury, except following a catastrophic event or natural disaster when scores are killed or injured, or only when a high-profile personality dies tragically. Negligible education of the public occurs, except in the context of questions raised about such events.

Correct terminology should be used by health professionals. There is general consensus among injury prevention advocates that the terms 'unintentional injury', 'intentional injury' (or 'violence' - self-inflicted, interpersonal, or collective), 'injury prevention', and 'injury control' are appropriate terms, rather than the use of the word 'accident'. Routine reference to a specific injury mechanism, such as motor vehicle crash, road traffic injury, fall, poisoning, or burn, rather than an 'accident' is better use of terminology. ${ }^{4}$

\section{What should health professionals know and do?}

- Develop knowledge of basic injury epidemiology theory and practice plus awareness of disparities in injury occurrence.

- Know major injury risks and leading injury causes (for South African data refer to Norman et al.). ${ }^{5}$

- Recognise that it costs less to prevent than treat an injury. ${ }^{4}$

- Attend to personal safety.

- Know what works in injury prevention. ${ }^{4}$

- Design basic injury prevention interventions by applying the Es of injury prevention:

- Education: Use The Haddon Ten principles of injury prevention; the Haddon Matrix and Haddon Matrix Third Dimension; and/or the SportSmart $\circledast 10$-point plan for sports injury prevention.

- Environment/engineering: Modify the physical and social environment. 4

- Enforcement: Support existing and appropriate new safety legislation. 4,6

- Emergency response: Know disaster response methods, first aid, and practise safety drills at home/work. ${ }^{6}$
- Evaluate: Begin injury surveillance and injury prevention programme evaluation.

- Create personal responsibility for injury in the minds of people. However, given that exclusive emphasis on personal responsibility can result in a climate of blame, attention should also be given to environmental as well as socio-cultural factors in injury causation. A complex area, models outlining ecological factors in injury causation (individual, interpersonal, community, and society) by Krug et al. (2002) and Hanson et al. (2005) are recommended reading. ${ }^{6}$ For further information about public health injury prevention refer to the references. 4,6

\section{Conclusion}

Unintentional and intentional injury are often overlooked but are leading causes of years of potential life lost and result in a severe burden to society. Health professionals can play an important public health role through increased personal responsibility and by including elements of injury prevention intervention, control, and safety promotion in daily activities. An effective injury prevention advocate needs to be informed about injury epidemiology, and should be seen to proactively and assertively encourage implementation of effective injury prevention strategies. Only then can we hope to see a decline in untimely death and disabling non-fatal injury.

\section{REFERENCES}

1. Holtzhausen LJ. Exercise is Medicine ${ }^{\circledR}$ in South Africa workshop: The way forward. 14th Biennial South African Sports Medicine Congress, October 2011.

2. Derman W. The responsibility of sport and exercise medicine in preventing and managing chronic disease: Applying our knowledge and skill is overdue. 14th Biennial South African Sports Medicine Congress, October 2011.

3. Injuries and Violence: the Facts. Geneva: World Health Organization, 2010. Available at: http://whqlibdoc.who.int/publications/2010/9789241599375_ eng.pdf (accessed 27 October 2011).

4. Christoffel T, Gallagher SS. Injury Prevention and Public Health, Practical Knowledge, Skills, and Strategies. 2nd ed. Boston: Jones and Bartlett, 2006.

5. Norman R, Matzopoulos R, Groenewald P, Bradshaw D. The high burden of injuries in South Africa. World Health Organization Bulletin 2007;85(9):695702. Available at: http://www.who.int/bulletin/volumes/85/9/06-037184-table-T1.html (accessed 27 October 2011).

6. Rorke SC. Prevention of injury during physical activity. International Journal of Body Composition Research 2010;7( Suppl.):45-50. (Suppl: Selected papers from the XXVth International Symposium of the International Council of Physical Activity and Fitness Research.) 